\title{
EIS STUDY OF BEER FERMENTATION EFFECTS ON CORROSION BEHAVIOR OF COPPER AND AUSTENITIC STAINLESS STEELS
}

\author{
Ehsan SAEBNOORI, Ondřej CHOCHOLATÝ, Pavel MICHÁLEK, Antonín KŘÍŽ \\ University of West Bohemia, Pilsen, Czech Republic, EU \\ saebnoor@kmm.zcu.cz, chochola@kmm.zcu.cz, Pavel.Michalek92@seznam.cz,kriz@kmm.zcu.cz
}

https://doi.org/10.37904/metal.2019.724

\begin{abstract}
Beer is a widely consumed alcoholic beverage throughout the world and global production figures have shown an increase in trend during the last decade. Many failures and corrosion problems encountered in brewery and fermentation process due to corrosivity of fluids which are rather acidic and also contain live microfauna. Presence of yeast and chloride ion can cause not only pitting corrosion but also microbiologically induced corrosion which lead to biofouling and failures.

In this study, the effect of fermentation products on corrosivity of copper and three austenitic stainless steel is evaluated by electrochemical methods. The metallic samples put into the fermenter vessel and several electrochemical impedance spectroscopy (EIS) tests performed during the fermentation and after that samples were removed from the fermenter and examined by optical microscope (OM) for detecting biofilm and corrosion products. Results showed that EIS curves have changed during the fermentation due to corrosion and biofilm formation.
\end{abstract}

Keywords: Brewing, Corrosion, Biofilm, Electrochemical tests, Corrosion products

\section{INTRODUCTION}

Beer is a widely consumed beverage around the world, made out of water, malt, hops and yeast as basic ingredients. Beer is more or less corrosive [1]. Not only is beer acidic, but also it contains live microfauna which can cause the biological corrosion.

Furthermore, any metal which has been used in the brewing system needs to cause no change in the taste and the smell of the product. In the interest of a better investment, it is also crucial to consider the value of the brewery equipment. Stainless steels and copper are commonly used for fermentation chambers, storage tanks and also piping systems. These materials are acid resistant and do not contaminate the beer.

Copper is a corrosion resistant alloy but it is more resistant to acid than alkaline. Copper alloys also have antibacterial properties however, it is weak to alkaline and oxidative sanitations along with scrubbing and wear weaknesses. Stainless steel has a better wear and corrosion resistance due to the formation of the passive oxide layer that protects the surface. On the other hand, stainless steel is susceptible to pitting corrosion in presence of chloride ions which is common in cleaning solutions. The 300 series alloys are commonly used in the brewing industry and basically, the passivated alloy is inert inserted to the beer [2,3].

In this paper, three austenitic stainless steel and one copper alloy which are mostly used in brewery, have been tested in beer during fermentation and the effects of biological process on corrosion resistance of alloys have been evaluated by Electrochemical Impedance Spectroscopy (EIS) method.

\section{MATERIALS AND METHODS}

The electrochemical cell was a galss container with a volume of $7 \mathrm{~L}$. The measurements were performed in a conventional three-electrode configuration under open-circuit conditions, requiring testing alloys as working electrod, a graphite rod as counter electrod and a saturated calomel electrode acting as reference electrode. 
The testing alloys connected with a wire, sealed in resin and well-defined area of $0.785 \mathrm{~cm}^{2}$ (a circle with the diameter of $10 \mathrm{~mm}$ ) of each working electrode was exposed to the electrolyte. The working electrodes were wet groundto 2000 -grit by SiC sand paper. A $99.9 \%$ pure copper and 304, 316 and 316L stainless steels were used as the testing alloys or working electrodes.

A malt solution with yeast used as electrolyte and EIS tests were performed during the fermentation with time intervals. Before starting the prosidure, the vesel was sanitated and filled with $5 \mathrm{~L}$ of boiled water while $0.8 \mathrm{~L}$ malt malt extract and SafAle US-05 yeast were added to the vesel. The cap of the vesel was sealed by a silicone waterproof glue and an airlock was used for checking the sealing.

The EIS tests were conducted using a SP-150 potentiostat, controlled by EC-lab software. The EIS measurements were obtained at Open Circuit Potential (OCP) with voltage perturbation amplitude of $10 \mathrm{mV}$ in the frequency range of $100 \mathrm{kHz}$ to $10 \mathrm{mHz}$. Figure 1, shows the schematic of laboratory experimental apparatus and fermentation setup.

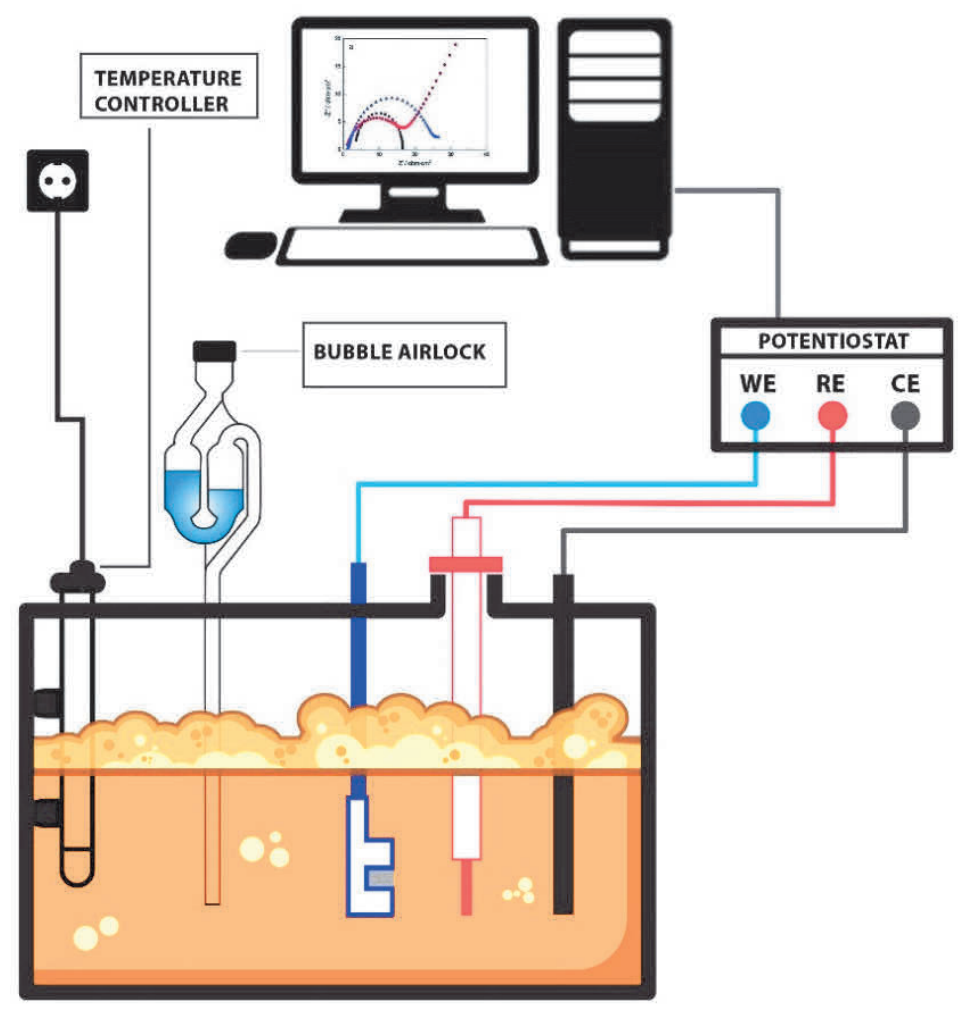

Figure 1 Schematic of laboratory experimental apparatus and fermentation setup

\section{RESULTS AND DISCUTION}

Figure 2, shows the impedance curve of copper, 304, 316 and 316L stainless steel. After the second day, huge changes in all of the curves have been observed. then the changes decreased and eventually, reached to a steady state condition. For the stainless steels, a defiusion control condition can be seen due to finite warburge element which is recognised as a diagonal line with a slope of $45^{\circ}$ at low frequencies[4]. For comparing the resistance in varoius tests, the maximum resistance at the lowest frequency exteracted from each curve (Table 1) and polted versus time in Figure 3. As is evidenced by this figure, the values of the resistance has a huge shift in copper after a day and subsequently, for countinuing the fermentation, it varied smoothly. Unlikely, stainless steels show less changes after first day and then reach a lower resistance for steady state situations. This can be assigned to aeration condition of vesel during the fermentation. In the begining of the fermentation the solution still contains oxygen which has a great effects on corrosion resistance 
of copper and stainless steel. Copper is a noble metal which is not passivated in oxidative condition. So, by continuing the fermentation, the oxygen in the cell is consumed and the cell enters to a desarated condition which increases the corrosion resistance. On the other hand, the less oxidative condition which caused by less soluble oxygen in the vessel makes the stainless steel more vulnarable to corrosion due to weak passive layer in reductive condition [5].
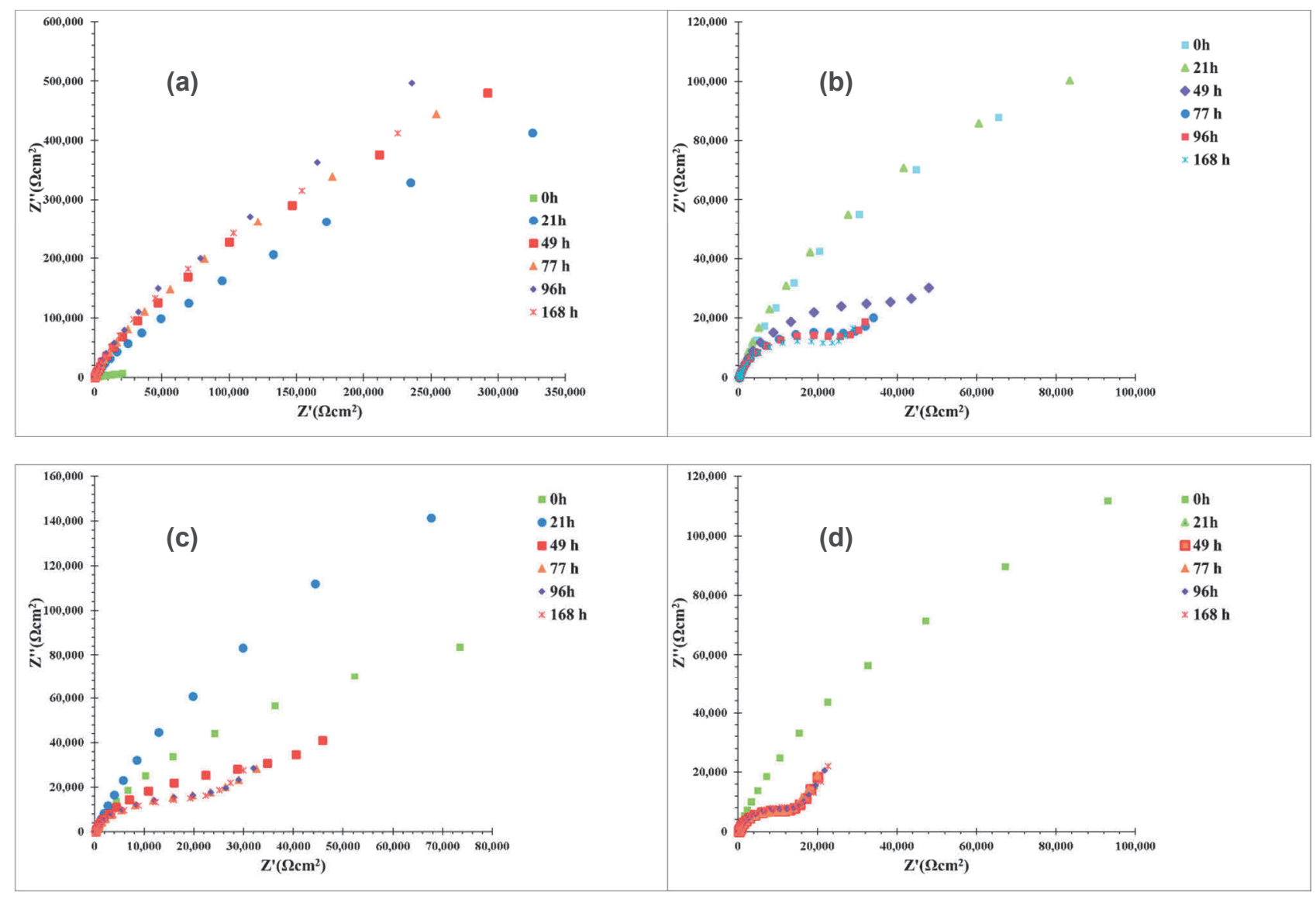

Figure 2 Nyquist curves for (a) copper, (b) 304, (c) 316 and (d) 316L stainless steel.

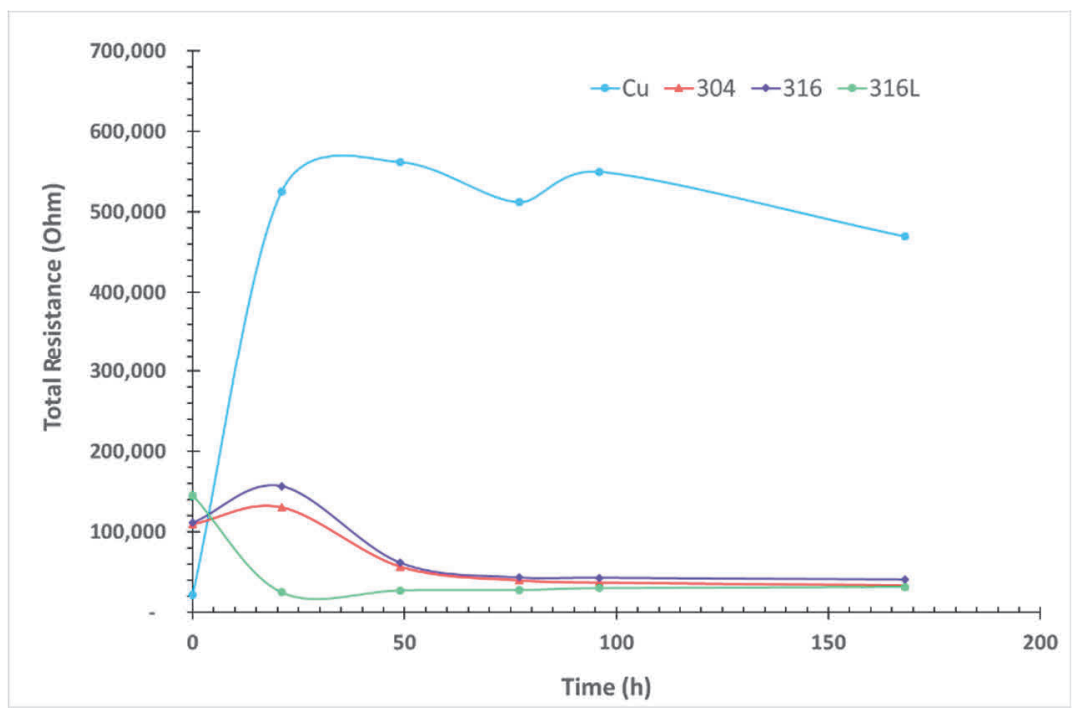

Figure 3 Resistance changes during the fermentation 
Table 1 Total resistance extracted from impedance curves for testing samples during the fermentation

\begin{tabular}{|c|c|c|c|c|}
\hline & Cu & $\mathbf{3 0 4}$ & $\mathbf{3 1 6}$ & 316L \\
\hline Time (h) & Resistance (ohm) & Resistance (ohm) & Resistance (ohm) & Resistance (ohm) \\
\hline 0 & 21,832 & 109,538 & 111,226 & 145,390 \\
\hline 21 & 525,468 & 130,422 & 156,713 & 24,690 \\
\hline 49 & 561,732 & 56,617 & 61,450 & 27,139 \\
\hline 77 & 511,955 & 39,555 & 43,204 & 27,643 \\
\hline 96 & 549,849 & 36,911 & 42,853 & 29,986 \\
\hline 168 & 469,478 & 33,298 & 40,694 & 31,567 \\
\hline
\end{tabular}

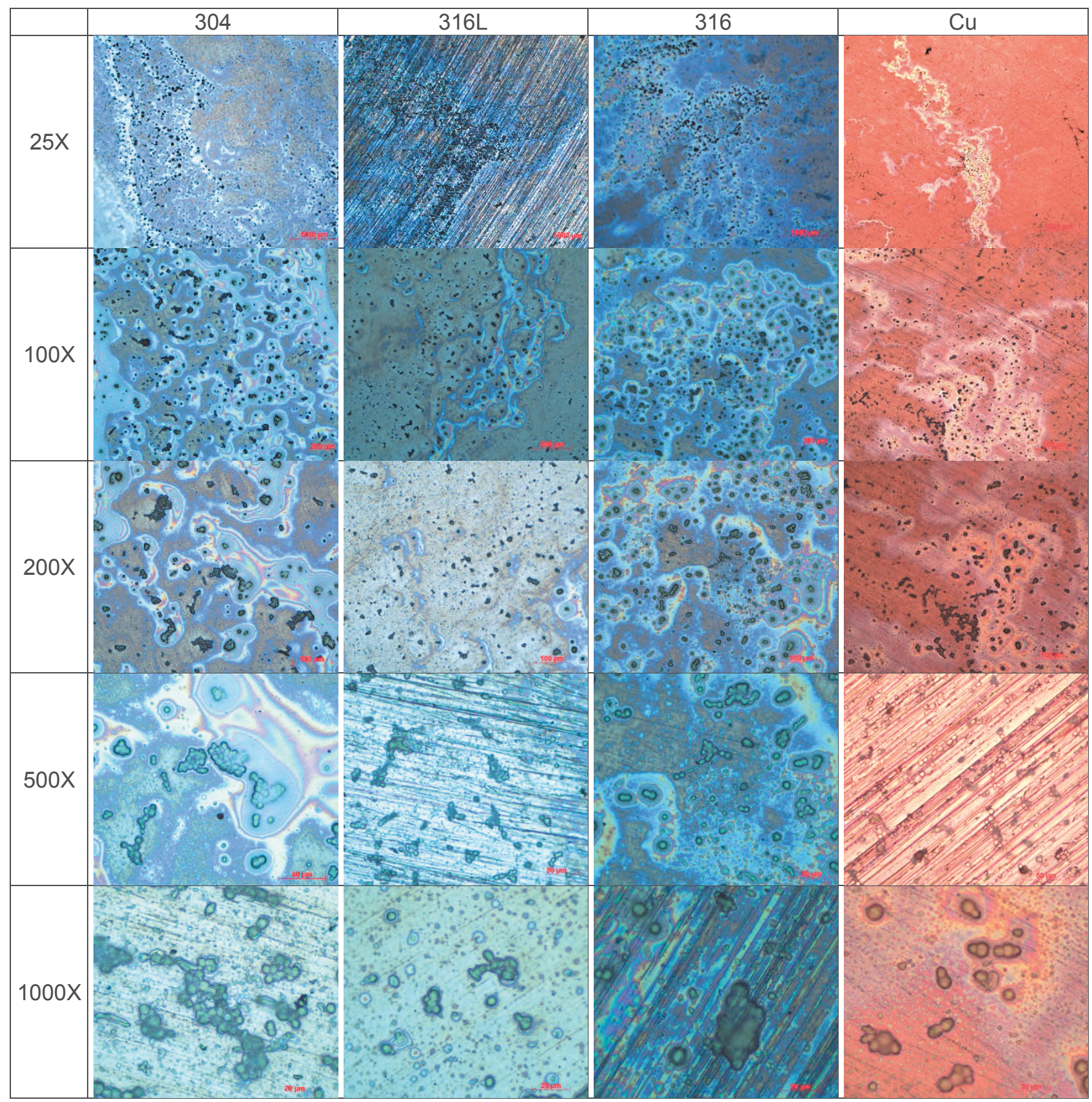

Figure 4 Optical microscope image of the yeast colony morphology and corrosion products after being exposed to fermentation solution for 200 hours 
Figure 4 shows the optical images of copper, 304, 316 and 316L stainless steel after 168 hours of suspention in the test setup. As can be seen, all of the samples are covered by a very thin corrosion products; also biofilm and the yeast cells can be observed in a higher magnification. It seems that, less colony of cells attached to the surface of copper rather than stainless steels which can be atributed to antibacterial effect of copper. Generally, it can be concluded that, the side effects of fermentation for decreasing the amount of soluble oxygen in the cell has more effects on the corrosion resistivity than formation of biofilms on the surface[6].

\section{CONCLUSION}

In this study, the effect of fermentation products on corrosivity of copper and three austenitic stainless steel are evaluated by electrochemical methods. The metallic samples put into the fermenter vessel and several electrochemical impedance spectroscopy (EIS) tests performed during the fermentation and after that, the samples are removed from the fermenter and are examined by optical microscope (OM) for detecting biofilm and corrosion products. Based on the EIS results, the changing in aeration condition has more effects than the biofilm formation and colony growth.

\section{ACKNOWLEDGEMENTS}

The presented work was financially supported by the Ministry of Education, Youth and Sport Czech Republic - project LQ1603 Research for SUSEN. This work has been realized within the SUSEN Project (established in the framework of the European Regional Development Fund (ERDF) in project CZ.1.05/2.1.00/03.0108 and of the European Strategy Forum on Research Infrastructures (ESFRI) in the project CZ.02.1.01/0.0/0.0/15_008/0000293.

\section{REFERENCES}

[1] J. ORLIKOWSKI and S. KRAKOWIAK, "Pitting corrosion and stress-corrosion cracking of buffer tanks in a brewery," Engineering Failure Analysis, vol. 29, pp. 75-82, 2013.

[2] T. REZIĆ, I. REZIĆ, I. BLAŽENOVIĆ, and B. ŠANTEK, "Optimization of corrosion process of stainless steel coating during cleaning in steel brewery tanks," Materials and corrosion, vol. 64, pp. 321-327, 2013.

[3] J. E. FRANTSEN, T. MATHIESEN, P. ALLE, K. U. HATTESEN, P. CHEEPSUJJAYAN, B. BERTELSEN, et al., "Common corrosion problems in the brewery sector," NACE Corrosion, 2008.

[4] K. PARK, S. AHN, and H. KWON, "Effects of solution temperature on the kinetic nature of passive film on Ni," Electrochimica Acta, vol. 56, pp. 1662-1669, 2011.

[5] A. ALIPOUR, A. BAHRAMI, and E. SAEBNOORI, "The effect of culture medium nutrients changing on inhibition property of c. Indologenes MUT. 2 bacterial biopolymer as a novel green corrosion inhibitor," University politehnica of bucharest scientific bulletin series b-chemistry and materials science, vol. 80, pp. 25-40, 2018.

[6] M. KHANI, A. BAHRAMI, and M. D. GHAFARI, "Optimization of operating parameters for anti-corrosive biopolymer production by Chryseobacterium Indologenes MUT. 2 using central composite design methodology," Journal of the Taiwan Institute of Chemical Engineers, vol. 59, pp. 165-172, 2016. 